the latter cut growth from 2 pct to 0.5 pct; 2 pct pitch eliminated growth, and 3 pct pitch showed about 0.3 pct shrinkage. Welght loss tests showed that most of the pitch volatilized a little above the melting point of copper.
Thus the coal tar pitch additive can be used to control dimensional changes of iron-copper compacts during sintering. It does not excessively harden the parts, so that they can be successfully sized.

\title{
Experiments on the Mechanism of Sintering
}

\author{
by $\mathrm{B} . \mathrm{H}$. Alexander \\ and \\ R. Balluffi
}

\begin{abstract}
$\mathrm{B}^{\mathrm{Y}}$ a method similar to that of Geech \& Jones ${ }^{1}$ the change in size and shape of the interstices between 5 mil copper wires has been followed as a function of time at various sintering temperatures. It has been found that the initial rate of decrease in the size of these voids is greater the higher the temperature. Upon sintering, the triangular cusp shaped voids between the wires become circular in cross-section and are connected to each other by grain boundaries. As long as these grain boundaries are present the voids continue to decrease in size. After a length of time, which decreases with increasing temperature, these grain boundaries disappear, and after their disappearance no further decrease in the size of the voids occurs. Because the grain boundaries disappear sooner at higher temperature, the overall decrease in the size of the voids is smaller, even
\end{abstract}

$B$. H. Alexander and $R$. Balluff are associated with Sylvania Electric Products, Inc., Bayside, L. I. though the initial rate of decrease is greater, at the higher temperatures.

We have concluded from these experiments that grain boundaries are essential for the sintering of powdered metal compacts, and that the finer the grain size, the more rapid sintering will occur. A series of experiments on powdered silver compacts is in progress, and it has been found that any treatment which can affect the initial recrystallization, and hence the grain size, of the pressed compacts will change the rate of sintering markedly. The effects of recovery at room temperature; recrystallization at low temperatures; rate of heating; and atmosphere are being studied in silver compacts, and it has been found that all of these can have a pronounced effect on the rate of sintering. An attempt is being made to explain these effects according to variations in grain size of the specimen.

${ }^{1}$ Research, Vol. 2, p. 493, 1949

\section{Interfaces in Diffusion in Solid Solutions}

\author{
by L. C. C. da Silva \\ and \\ R. F. Mehl
}

\begin{abstract}
$T_{0}$ HIS is an experimental study of the movement of markers during diffusion in solid solutions, the phenomenon discovered by Kirkendall and theoretically studied by Seitz, Darken, Bardeen, and others. Six systems have been investigated, at a series of temperatures: $\mathrm{Cu} / a$ brass; $\mathrm{Cu} / \mathrm{Sn}-a$ solid solution; $\mathrm{Cu} / \mathrm{Al}-\alpha$ solid solution; $\mathrm{Cu} / \mathrm{Ni}$; $\mathrm{Ag} / \mathrm{Au} ; \mathrm{Cu} / \mathrm{Au}$ diffusion couples have been

L. C. C. da Silva and R. F. Mehl are associated with the Dept. of Metallurgical Engineering at Carnegie Institute of Technology, Pittsburgh, Pa.
\end{abstract}

made by welding. Markers of many types have been used, including $\mathrm{W}, \mathrm{Mo}, \mathrm{Ni}, \mathrm{Pt}$ wires; $\mathrm{Pt}, \mathrm{Ta}, \mathrm{W}, \mathrm{Fe}, \mathrm{Ni}$, foils; C, $\mathrm{Al}_{2} \mathrm{O}_{3}, \quad \mathrm{Fe}_{2} \mathrm{O}_{3}$ powders. All markers move, and by the same amount in a given system, the phenomenon is thus not a property of the marker; the movement, with respect to the Matano interface, has been measured for the separate systems. In the $\mathrm{Cu} / \alpha$ brass couples, the markers move toward the high $\mathrm{Zn}$ side; in the $\mathrm{Cu} / \mathrm{A} 1$ system, toward the high Al side; in the $\mathrm{Cu} / \mathrm{Sn}$ system, toward the high $\mathrm{Sn}$ side; in the $\mathrm{Cu} / \mathrm{Ni}$ system, toward the $\mathrm{Cu}$; in the $\mathrm{Ag} / \mathrm{Au}$ system, toward the $\mathrm{Ag}$; in the 